\title{
VARIEDADES
}

\section{TKFĀT AL-BARBARIYYA Y EL DESTINO DE LOS OMEYAS EN AL-ANDALUS ${ }^{1}$}

\author{
Maribel FIERRO \\ CSIC - Madrid
}

Tras la caída del califato omeya de Damasco a manos de los 'abbāsíes, un miembro de la familia, 'Abd al-Rahmmān b. Mu'āwiya, que habría de convertirse en el primer emir omeya de al-Andalus, huyó en dirección a Occidente, decisión en la que influyó sin duda el origen beréber de su madre. El relato más detallado de las vicisitudes de su huida se ha conservado en el anónimo Dikr bilād al-Andalus ${ }^{2}$ :

La causa de que el imán 'Abd al-Raḥmān entrara en al-Andalus y lo dominara fue que, cuando los 'abbāsíes vencieron y fueron proclamados califas, siendo asesinado Marwān al-Ŷya dī, los ejércitos omeyas se dispersaron, su linaje se diseminó, sus mujeres fueron deshonradas y fueron presa todos ellos de un gran terror. 'Abd al-Raḥmān b. Mu'āwiya logró salir huyendo y se encaminó hacia Egipto con cuatro mawlàs suyos, Badr, Tammām, Ziyād y Abū Šuŷā'. Allí permaneció unos días, pero llegó un escrito de al-Ṣaffāḥ [el califa 'abbāsí] al gobernador de Egipto en el que le ordenaba buscar a los omeyas huidos, por lo que 'Abd al-Rahmān tuvo que salir a escondidas con sus mawlàs y dirigirse a Barqa, donde esperaron unos días hasta que se olvidó el asunto y les fue posible encaminarse a Ifriquiya. Una vez allí entraron en Qayrawān, donde se hallaba como gobernador de los habitantes de Ifríqiya 'Abd al-Raḥmān b. Ḥabỉb al-Fihrī. 'Abd al-Raḥmān se aposentó entre los Banū Mugīt, mawlàs de su abuelo 'Abd al-Malik b. Marwān, donde encontró una acogida amable y extremadamente hospitalaria, pero fue denunciado ante 'Abd al-Raḥmān b. Habīb y éste ordenó buscarle. Como no tuviera éxito en sus pesquisas, hizo que se investigara por todo el país de Ifriqiya para descubrirlo, e incluso puso espías y vigilantes en todos los caminos

\footnotetext{
${ }^{1}$ Quiero agradecer a Luis Molina su ayuda en la redacción de esta variedad.

2 Ed. y trad. L. Molina, 2 vols., Madrid, 1983, I, 110-1 (texto árabe), II, 118-9 (traducción): sigo la traducción de L. Molina, indicando dos correcciones que me han sido señaladas por el propio traductor. No hay datos respecto a cuál es la fuente original de este relato, como tampoco del que recojo a continuación procedente del Nafh.
}

Al-Qanțara XXII, 2 (2001) 345-348 
y amenazó a todos los sospechosos, tanto a los Banū Mugīt como a otros, pero 'Abd al-Raḥmān se hallaba escondido entre las mujeres. Más tarde reemprendió la huida hasta que llegó a la residencia de Abū Qurra al-Barbarī, pero el emir descubrió el escondite y forzó la entrada de la casa. La mujer de Abū Qurra se echó entonces sobre 'Abd al-Raḥmān y lo introdujo debajo de sus vestidos; a continuación se soltó las trenzas y empezó a peinarse. Era una mujer muy gruesa ${ }^{3}$ y cuando los pesquisidores llegaron ante ella y la encontraron de esa guisa, empezó a llorar y se recogió las ropas ${ }^{4}$; ellos, que temían a su marido, salieron de la estancia sin haber podido apresar a 'Abd al-Rạ̣mān, a quien Dios libró de ellos.

Más tarde abandonó la casa de Abū Qurra y llegó a la tribu de Nafza, donde se aposentó en casa de sus tíos maternos, con los que permaneció unos días. De allí se trasladó a Zanāta, deteniéndose en una aldea costera llamada Magïla ${ }^{5}$, desde donde comenzó a escribir a al-Andalus y a organizar su pase a la Península.

El episodio de cómo 'Abd al-Raḥmān se escondió entre las ropas de la mujer de Abū Qurra es referido también por al-Maqqarī ${ }^{6}$, en un pasaje en el que además se nos da el nombre de esa mujer, Tkfāt al-Barbariyya ${ }^{7}$, así como el nombre completo de su marido, Abū Qurra Wānsūs b. Yarbū'. El pasaje en cuestión nos sitúa en el momento en que Abū Qurra y su mujer pasan a al-Andalus una vez que 'Abd al-Raḥmān I se hubo hecho con el poder allí. El omeya mostró especial respeto y agradecimiento a Tkfāt, pues ella le ocultó bajo sus ropas cuando los enviados de Ibn Habỉb [el gobernador de Ifriqiya] registraron su casa buscándole. 'Abd al-Raḥmān I le dijo bromeando cuando ella buscó su protección en al-Andalus:

«Encima del miedo que tenía, tuve que soportar que me atormentases con el olor de tus axilas, ¡oh Tkfāt!, y me hiciste aspirar un hedor más nauseabundo que el de un cadáver putrefacto». La respuesta de ella fue rápida: «Por el contrario, ¡oh, señor!, eras tú el causante del hedor, aunque no te dieras cuenta, resultado del miedo tan terrible que estabas pasando». Encontró donosa la respuesta de ella y dejó pasar la cosa sin hacer lo que se hubiera merecido una contestación como ésa. Éstas son las cosas de andar con bromas.

${ }^{3}$ Hay que añadir «y alta».

${ }^{4}$ Mejor: «se cubrió, envolviéndose en sus ropas».

${ }^{5}$ Otras fuentes sitúan a Abū Qurra en Magìla: v. de Felipe, H., Identidad y onomástica de los beréberes de al-Andalus, Madrid, 1997, 231.

${ }^{6}$ Nafḥ al-țỉb, ed. I. 'Abbās, 8 vols., Beirut, 1968, I, 333-4. Sobre los Banū Wānsūs y sus conexiones posteriores con los omeyas v. de Felipe, Identidad y onomástica, 230-8.

${ }^{7}$ V. sobre ella Marín, M., Mujeres en al-Andalus, Madrid, 2000 (EOBA, XI), 52, 486, 487. 
Aunque no se debe exagerar la influencia del acto de Tkfāt ${ }^{8}$ en el destino de 'Abd al-Rahmān I y en el establecimiento omeya en al-Andalus, tampoco se puede pasar por alto. Su importancia va más allá, en mi opinión, del mero hecho de haber ocultado al fugitivo de quienes podían haberlo capturado y haber acabado con su vida o al menos haberla puesto en peligro. En efecto, en el acto de Tkfāt puede verse el eco de prácticas de la mujeres beréberes atestiguadas en el norte de África que tienen que ver con el ofrecimiento de asilo y con la creación de unas obligaciones con el protegido que involucran al grupo tribal al que pertenece la mujer. Las prácticas son descritas por E. Westermarck:

... a woman is hórma - she must not be touched. The Shlöh say, Tamgart zud agurram, «A woman is like a saint». She may serve as an asylum: a person who takes refuge with a woman, placing himself in her ' $\bar{a} r$ [conditional curse], for the moment is safe from his pursuer and must afterwards be protected by her husband or family. I have found this custom among the various groups of Berber-speaking people...

A refugee places himself in the ' $\bar{a} r$ of a woman by touching her or sucking her breast... - by which he becomes as it were her son- or by sitting down in front of her or going behind her or running into her house and taking hold of the handmill...; her husband or family will then have to help him... The following case occurred in a village in Andjra where I was staying. A man who had committed murder came running to the village, pursued by the relatives of his victim. He found in a field some women belonging to the family of my host, a highly respected shereef, and cried out, Ana mzâug flláh u fi -š-šrî̉, «I am seeking refuge with God and the shereef». Without touching them he lay down on the ground, and they covered him with some of their clothes, and this prevented the pursuers from carrying out their intented revenge and made them turn back to their village ${ }^{9}$.

Cuando Tkfāt al-Barbariyya escondió a 'Abd al-Raḥmān b. Mu'āwiya cubriéndolo con sus ropas ${ }^{10}$, inició el establecimiento de una red de obligaciones entre el perseguido y los hombres de su familia ${ }^{11}$ que, sin duda, contribuyeron a que el omeya se sintiera seguro en su refugio norteafricano y pudiera lle-

${ }^{8}$ Y de las mujeres de los Banū Mugīt, entre las que se escondió el omeya.

${ }^{9}$ Westermarck, E., Ritual and belief in Morocco, 2 vols., Londres, 1926, I, 490, 522.

${ }^{10}$ En el primer relato parece deducirse que el omeya se escondió debajo de las ropas que ella tenía puestas, mientras que del segundo podría deducirse que lo escondió debajo de unas ropas que no eran necesariamente las que ella llevaba.

${ }^{11}$ A lo que habría que añadir que, según algunas fuentes, los Banū Wānsūs ya eran en ese momento clientes de los omeyas. Pero lo eran en general los beréberes, por haber sido conquista- 
var a cabo con éxito los preparativos para pasar a la Península. Una vez que hubo alcanzado el poder, extendió su protección a los Banū Wānsūs. El intercambio de bromas entre Tkfāt y 'Abd al-Raḥmān I, que parece despertar la incomprensión de al-Maqqaīi por no responder al respeto que se debe mostrar a un gobernante, no hace sino reflejar el hecho de que, en ese momento, el que tenía una deuda que pagar era el omeya.

No es éste el único caso en que vemos a miembros de los Banū Wānsūs extendiendo su protección. Durante la revuelta del Arrabal, 'Abd Allāh b. Wānsūs concedió asilo en su mezquita a un grupo de revoltosos que se habían refugiado en ella. Solicitó al emir al-Hakam I el perdón para ellos, petición que le fue concedida ${ }^{12}$.

\footnotetext{
do su territorio durante el califato omeya, y ello no impidió las rebeliones contra sus patronos. Un miembro de los Banū Wānsūs también se rebeló en al-Andalus contra el emir omeya: v. de Felipe, Identidad y onomástica, 232.
}

${ }^{12}$ De Felipe, ob. cit., 232. 